\title{
Low Risk of Hepatitis B Virus Reactivation in HBsAg-negative / Anti-HBc-positive Carriers Receiving Rituximab for Rheumatoid Arthritis: A Retrospective Multicenter Italian Study
}

\author{
Valentina Varisco, Mauro Viganò, Alberto Batticciotto, Pietro Lampertico, Antonio Marchesoni, \\ Patrizia Gibertini, Raffaele Pellerito, Guido Rovera, Roberto Caporali, Monica Todoerti, \\ Michele Covelli, Antonella Notarnicola, Fabiola Atzeni, and Piercarlo Sarzi-Puttini
}

\begin{abstract}
Objective. Patients with resolved hepatitis B virus (HBV) infection, i.e., hepatitis B surface antigen (HBsAg)-negative/antihepatitis B core antigen (anti-HBc)-positive, undergoing rituximab (RTX)-based chemotherapy for hematological malignancies without anti-HBV prophylaxis are at risk of HBV reactivation, but the risk in such patients receiving RTX for rheumatological disorders is not clear. We evaluated this risk in $\mathrm{HBs} \mathrm{Ag}$-negative/anti-HBc-positive patients with rheumatoid arthritis (RA) undergoing RTX without prophylaxis.

Methods. Thirty-three HBsAg-negative/anti-HBc-positive outpatients with RA with undetectable HBV DNA by sensitive PCR assay [73\% women, median age 60 years, $85 \%$ with HBsAg antibodies (anti-HBs), $37 \%$ with antihepatitis B envelope antigen] received a median of 3 cycles of RTX (range 1-8) over 34 months (range 0-80) combined with disease-modifying antirheumatic drugs (DMARD) without prophylaxis. All underwent clinical and laboratory monitoring during and after RTX administration, including serum HBsAg and HBV DNA measurements every 6 months or whenever clinically indicated.

Results. None of the patients seroreverted to HBsAg during RTX treatment, but 6/28 (21\%) showed a $>50 \%$ decrease in protective anti-HBs levels, including 2 who became anti-HBs-negative. One patient (3\%) who became HBV DNA-positive (44 IU/ml) after 6 months of RTX treatment was effectively rescued with lamivudine before any hepatitis flare occurred. Among the 14 patients monitored for 18 months (range 0-70) after RTX discontinuation, no HBV reactivation was observed.

Conclusion. The administration of RTX + DMARD in patients with RA with resolved HBV infection leads to a negligible risk of HBV reactivation, thus suggesting that serum HBsAg and/or HBV DNA monitoring but not universal anti-HBV prophylaxis is justified. (First Release February 15 2016; J Rheumatol 2016;43:869-74; doi:10.3899/jrheum.151105)
\end{abstract}

Key Indexing Words:

HEPATITIS B VIRUS REACTIVATION

RITUXIMAB

HBsAg HBV DNA

Rituximab (RTX) is a genetically engineered chimeric murine/human monoclonal antibody that targets CD20-positive cells by inducing the profound depletion of physiological
B lymphocytes. It is indicated for the treatment of patients with non-Hodgkin lymphoma, chronic lymphocytic leukemia, granulomatosis with polyangiitis, microscopic
From the Rheumatology Unit, Ospedale L. Sacco; Hepatology Unit, Ospedale San Giuseppe, University of Milan; A.M. and A. Migliavacca Center for Liver Disease, Division of Gastroenterology and Hepatology, Fondazione Istituto di Ricovero e Cura a Carattere Scientifico (IRCCS) Ca' Granda Ospedale Maggiore Policlinico, University of Milan; Rheumatology Day Hospital, Istituto Ortopedico G. Pini, Milan; Rheumatology Unit, Ospedale Mauriziano, Turin; Rheumatology Division, IRCCS Fondazione San Matteo, Università di Pavia, Pavia; University Rheumatology Department, Azienda Ospedaliero Universitaria (AOU) Policlinico, Bari, Italy.

V. Varisco*, MD, Rheumatology Unit, Ospedale L. Sacco; M. Viganò* MD, Hepatology Unit, Ospedale San Giuseppe, University of Milan; A. Batticciotto, MD, PhD, Rheumatology Unit, Ospedale L. Sacco; P. Lampertico, MD, PhD, Professor, A.M. and A. Migliavacca Center for Liver Disease, Division of Gastroenterology and Hepatology, Fondazione IRCCS Ca' Granda Ospedale Maggiore Policlinico, University of Milan;
A. Marchesoni, MD, Rheumatology Day Hospital, Istituto Ortopedico G. Pini; P. Gibertini, MD, Rheumatology Day Hospital, Istituto Ortopedico G. Pini; R. Pellerito, MD, Rheumatology Unit, Ospedale Mauriziano; G. Rovera, MD, Rheumatology Unit, Ospedale Mauriziano; R. Caporali, MD, Professor, Rheumatology Division, IRCCS Fondazione San Matteo, Università di Pavia; M. Todoerti, MD, Rheumatology Division, IRCCS Fondazione San Matteo, Università di Pavia; M. Covelli, MD, University Rheumatology Department, AOU Policlinico; A. Notarnicola, MD, University Rheumatology Department, AOU Policlinico; F. Atzeni, MD, PhD, Rheumatology Unit, Ospedale L. Sacco; P. Sarzi-Puttini, MD, Rheumatology Unit, Ospedale L. Sacco. *These authors contributed equally to the study.

Address correspondence to Dr. Piercarlo Sarzi-Puttini, UOC Reumatologia, Ospedale L. Sacco, Via G.B. Grassi 74, 20157 Milano, Italy.E-mail: sarzi.piercarlo@hsacco.it

Accepted for publication January 9, 2016.

Personal non-commercial use only. The Journal of Rheumatology Copyright @ 2016 . All rights reserved. 
polyangiitis, and since 2006 for patients with rheumatoid arthritis (RA) refractory to 1 or more disease-modifying antirheumatic drugs (DMARD) and antitumor necrosis factor (TNF) agents ${ }^{1,2,3,4}$. However, when used alone or in combination with immunosuppressive drugs, the long-lasting B lymphocyte depletion has been associated with an increased risk of infection, including the reactivation of viral infections ${ }^{5}$. Fatal hepatitis B virus (HBV) reactivation has been reported not only among patients with overt HBV infection, i.e., those who are hepatitis B surface antigen (HBsAg)-positive, but also in patients with resolved HBV infection, i.e., those who are $\mathrm{HBsAg-negative} \mathrm{and} \mathrm{antihep-}$ atitis $\mathrm{B}$ core antigen (anti-HBc)-positive, regardless of the presence of antibodies against HBsAg (anti-HBs) ${ }^{6}$. Among the latter group, ongoing low levels of HBV transcription and replication in liver cells increases the risk of reactivation upon intense immunosuppression with cytotoxic drugs ${ }^{7,8}$. The current RTX label therefore includes a black box warning concerning the risk of HBV reactivation, and recommends that all patients should be screened for the serum markers of HBV infection before starting RTX therapy, and monitored during and after treatment ${ }^{9}$.

HBV reactivation has been reported in up to $20 \%$ of HBsAg-negative/anti-HBc-positive carriers with oncohematological diseases undergoing RTX-based chemotherapy without antiviral prophylaxis ${ }^{10,11,12}$, but little is known about the risk and its clinical consequences in patients with resolved HBV infection treated with RTX for rheumatological diseases, and the international guidelines do not agree as to how such patients should be managed ${ }^{13,14,15}$. Two studies out of a total of $26 \mathrm{HBsAg-negative/anti-HBc-positive} \mathrm{carriers}$ treated with RTX for rheumatic disease have found no risk of $\mathrm{HBV}$ reactivation ${ }^{16,17}$, but 2 cases of $\mathrm{HBsAg}$ seroreversion, i.e., reappearance of serum HBsAg, after starting RTX and methotrexate (MTX) in 1 and after RTX plus prednisone (PRED) in the other have been described in patients with RA with resolved HBV infection ${ }^{18,19}$.

We evaluated the incidence, clinical effect, and risk factors of $\mathrm{HBV}$ reactivation in $33 \mathrm{HBsAg}$-negative/anti-HBc-positive patients with RA treated with RTX plus DMARD in the absence of anti-HBV prophylaxis in an attempt to gain further insights.

\section{MATERIALS AND METHODS}

Patients. We retrospectively studied 306 consecutive patients with RA who received RTX-based treatment in 5 Italian Rheumatological Outpatient Clinics from August 2006 to December 2011. The results of complete pre-RTX serological screening for HBsAg, anti-HBs, anti-HBc, antihepatitis B envelope antigen (anti-HBe), and serum HBV DNA were available for 216 patients $(70 \%), 39(18 \%)$ of whom were negative for HBsAg and positive for anti-HBc. Six of these patients had received lamivudine (LMV) as antiviral prophylaxis and were excluded from the study, which therefore involved a total of 33 patients (Figure 1). None of the enrolled patients were previously treated with antiviral agents, either before diagnosis of RA or during immunosuppressive therapies before starting RTX.

The patients' demographic, clinical, and virological characteristics, their
306 patients with RA who underwent RTX-based treatment from Augus

2006 to Decembrer 2011 in 5 Italian outpatient rheumatological clinics

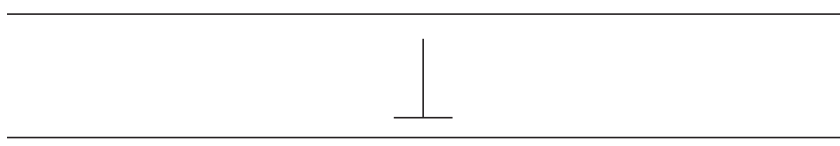

216 patients $(70 \%)$ had HBV markers available at start of RTX

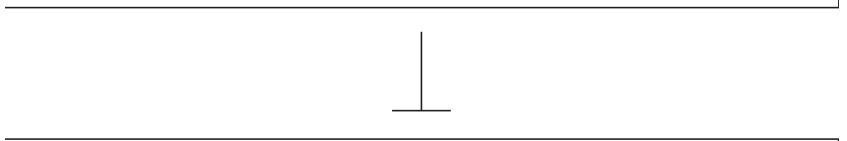

39 patients (18\%) were HBsAg-negative/anti-HBc-positive

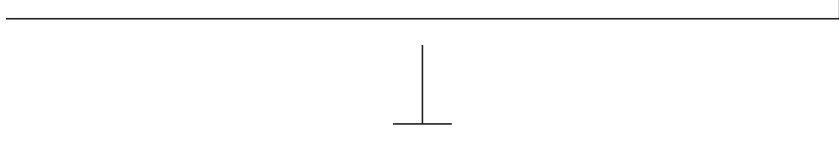

33 HBsAg-negative/anti-HBc-positive patients did not undergo anti-HBV prophylaxis and were included in the study

Figure 1. Study flow chart. RA: rheumatoid arthritis; RTX: rituximab; HBV: hepatitis B virus; HBsAg: hepatitis B surface antigen; anti-HBc: antihepatitis $\mathrm{B}$ core antigen.

previous and/or concurrent DMARD therapy (MTX, leflunomide, azathioprine, cyclosporine), corticosteroid therapy (PRED-equivalent dose), and previous biological treatment for RA, the results of liver function tests, and complete serological screening for hepatitis $\mathrm{C}$ virus $(\mathrm{HCV})$ were recorded.

In accordance with international guidelines ${ }^{20,21}$, RTX was administered at the standard intravenous (IV) dose of $1000 \mathrm{mg}$ on days 1 and 15 every 6 months, or on the basis of the patients' clinical responses. All patients received high dose methylprednisolone (100 mg IV) at each RTX administration as recommended on the label of the drug. All patients were followed up during RTX treatment by means of clinical and laboratory examinations, including serum HBsAg and HBV DNA measurements, which were assessed at least every 6 months whenever alanine aminotransferase (ALT) levels exceeded the upper limit of normal (ULN), or at the last followup visit before December 2014. The same scheduled examinations were also carried out during the posttreatment followup of the patients who discontinued RTX. Consequently, a total of 250 laboratory examinations were carried out during the study period, including the on- and off-treatment followup (a median of 8 per patient, range $2-14$ ).

Serum assays. Serum ALT and aspartate aminotransferase levels were automatically measured at $37^{\circ} \mathrm{C}$. To avoid bias because of the use of different normal values, ALT levels were expressed as the value observed in the patient (IU/l) and the ULN as the local ULN. HBsAg, anti-HBs, anti-HBc, and anti-HBe were assessed using a microparticle enzyme immunoassay (AXSYM, Abbott Laboratories), and anti-HCV using a second-generation ELISA (Ortho Diagnostic System); serum HCV RNA was quantified by means of real-time PCR (Amplicor HCV; Roche Molecular Systems, Inc.) with a lower limit of quantification of $50 \mathrm{IU} / \mathrm{ml}$. HBV DNA was assessed using the COBAS Amplicor HBV Monitor Test (v2.0, Roche Diagnostics) with a lower limit of quantification of $71 \mathrm{IU} / \mathrm{ml}$ in 1 center, and the real-time COBAS TaqMan HBV Test (v2.0, Roche Molecular Systems, Inc.) with a lower limit of quantification of $10 \mathrm{IU} / \mathrm{ml}$ in the other 4 .

Endpoints. The primary study endpoint was the HBV reactivation rate: i.e., the appearance of serum HBsAg (HBsAg seroreversion) or serum HBV DNA without HBsAg seroreversion. The secondary endpoints were the percentage of patients with normal ALT levels at baseline whose levels

Personal non-commercial use only. The Journal of Rheumatology Copyright $\odot$ (2016. All rights reserved 
increased to above the ULN; the percentage of patients with protective anti-HBs titers (> $10 \mathrm{IU} / \mathrm{l})$ at baseline who showed $\mathrm{a}>50 \%$ reduction during treatment; the onset of acute hepatitis B, defined as HBsAg seroreversion with $\mathrm{a}>10$-fold increase in serum ALT levels and HBV DNA $>5 \log _{10}$ $\mathrm{IU} / \mathrm{ml}$; and chronic HBV infection, defined as the persistence of serum HBsAg for at least 6 months.

Statistical analysis. The qualitative variables are expressed as counts and percentages, and the discrete variables as median values and ranges. The differences in their distribution were respectively evaluated using Fisher's exact test and Wilcoxon signed-rank test. All p values are 2-tailed, and a value of 0.05 was considered statistically significant. The data were statistically analyzed using STATA software (release 7.0., Stata Corporation).

\section{RESULTS}

Baseline. Table 1 shows the patients' baseline demographic, clinical, and virological characteristics. The majority of patients were middle-aged women who had had rheumatic disease for a median of 8 years. All patients had negative baseline serum HBV DNA levels as assessed by sensitive PCR assay. Twenty-eight patients $(85 \%)$ had protective pre-RTX anti-HBs titers, and $2(6 \%)$ had chronic HCV infection with baseline HCV RNA levels of, respectively,

Table 1. Baseline demographic, clinical, and virological characteristics of 33 HBsAg-negative/anti-HBc-positive patients with RA. Values are n (\%) unless otherwise specified.

\begin{tabular}{|c|c|}
\hline Characteristic & Value \\
\hline Age, yrs, median (range) & $60(30-80)$ \\
\hline Females & $24(73)$ \\
\hline Protective anti-HBs titer, > $10 \mathrm{IU} / 1$ & $28(85)$ \\
\hline Anti-HBs titer, IU/1, median (range)* & $285(18$ to $>1000)$ \\
\hline Anti-HBe-positive patients** & $10(37)$ \\
\hline ALT level, IU/1, median (range) & $27(10-113)$ \\
\hline ALT levels $<$ ULN & $29(88)$ \\
\hline 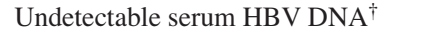 & $33(100)$ \\
\hline Anti-HCV-positive patients & $2(6)$ \\
\hline Duration of RA, yrs, median (range) & $8(1-30)$ \\
\hline \multicolumn{2}{|l|}{ Antirheumatic therapies before RTX, $\%^{\ddagger}$} \\
\hline MTX & 83 \\
\hline PRED & 80 \\
\hline CSA & 26 \\
\hline LEF & 8 \\
\hline AZA & 6 \\
\hline IFX & 40 \\
\hline ETN & 36 \\
\hline ADA & 15 \\
\hline $\mathrm{ABA}$ & 3 \\
\hline Anakinra & 3 \\
\hline \multicolumn{2}{|c|}{ Antirheumatic therapy at time of starting RTX, \% } \\
\hline MTX & 36 \\
\hline MTX + PRED & 64 \\
\hline
\end{tabular}

* Among patients with protective anti-HBs titers. ** Out of 27 patients. ${ }^{\dagger}$ PCR assay. ${ }^{\ddagger}$ The sum of treatments is greater than $100 \%$. HBsAg: hepatitis B surface antigen; anti-HBc: antihepatitis B core antigen; RA: rheumatoid arthritis; anti-HBs: HBsAg antibodies; anti-HBe: antihepatitis B envelope antigen; ALT: alanine aminotransferase; ULN: upper limit of normal; HBV: hepatitis B virus; HCV: hepatitis C virus; RTX: rituximab; MTX: methotrexate; PRED: prednisone; CSA: cyclosporine; LEF: leflunomide; AZA: azathioprine; IFX: infliximab; ETN: etanercept; ADA: adalimumab; ABA: abatacept.
340,000 and $1,236,000 \mathrm{IU} / \mathrm{ml}$. Only 4 patients $(12 \%)$ had ALT values above the $\operatorname{ULN}(2.5,1.5,1.3$, and $1.1 \times \mathrm{ULN})$. All patients had been previously treated with 1 or more DMARD and/or different biological drugs.

RTX was administered for a median of 3 cycles (range 1-8), in combination with MTX at a median dose of $10 \mathrm{mg} /$ week (12 patients, 36\%) or PRED 5-7.5 mg/day plus MTX $10 \mathrm{mg} /$ week (21 patients, 64\%).

Virological and clinical events during RTX administration. During the median 34 months of RTX treatment (range 0-80), no patient experienced HBsAg seroreversion, but 6 out of $28(21 \%)$ with baseline protective anti-HBs titers showed a $>50 \%$ decrease in anti-HBs levels, including 2 patients who become anti-HBs-negative.

One 50-year-old, anti-HBe-negative woman (3\%) showed low serum HBV DNA levels $(44 \mathrm{IU} / \mathrm{ml}) 6$ months after the first cycle of RTX without HBsAg seroreversion or an increase in ALT levels, and her anti-HBs titer decreased to below the protective level (from 92 to 7 IU/l). Treatment with LMV $100 \mathrm{mg} /$ day promptly led to undetectable viral replication, which was maintained during the subsequent 30 months of RTX treatment (6 cycles) without any HBsAg seroreversion (Figure 2).

Four (14\%) of the 29 patients with normal baseline ALT levels experienced an increase to above the ULN; this was transient in 3 patients (up to a maximum of 1.1, 1.2, and 1.5 $\times$ ULN), but continued until the end of RTX treatment in 1 (up to a maximum of $6 \times \mathrm{ULN}$ ). However, none of these patients experienced HBV reactivation. Among the 4 patients whose baseline ALT levels were above the ULN (including the 2 patients with chronic HCV infection), the levels normalized in $3(75 \%)$ and remained slightly high $(1.3 \times$ ULN) throughout the followup in 1 of the patients with chronic hepatitis $\mathrm{C}$.

Virological and clinical events after RTX administration. By the end of the followup period, RTX treatment had been discontinued in 14 patients (42\%) after a median of 3 cycles (range 1-6) over a median of 22 months (range 0-80), none of whom experienced HBV reactivation during a median 18 months of posttreatment followup (range 0-70). The remaining 19 patients (58\%) continued the treatment.

\section{DISCUSSION}

The findings of our study indicate that the risk of HBV reactivation is negligible in patients with RA with resolved HBV infection treated with RTX + DMARD without anti-HBV prophylaxis.

It is well known that HBsAg-positive patients and HBsAg-negative/anti-HBc-positive carriers receiving RTX-based chemotherapy for oncohematological diseases require antiviral treatment or universal prophylaxis with anti-HBV nucleos(t)ide analogs (NUC) before immunosuppressive treatment to prevent $\mathrm{HBV}$ reactivation ${ }^{6}$, which occurs in nearly $20 \%$ of cases and may lead to the inter-

Personal non-commercial use only. The Journal of Rheumatology Copyright (c) 2016. All rights reserved. 


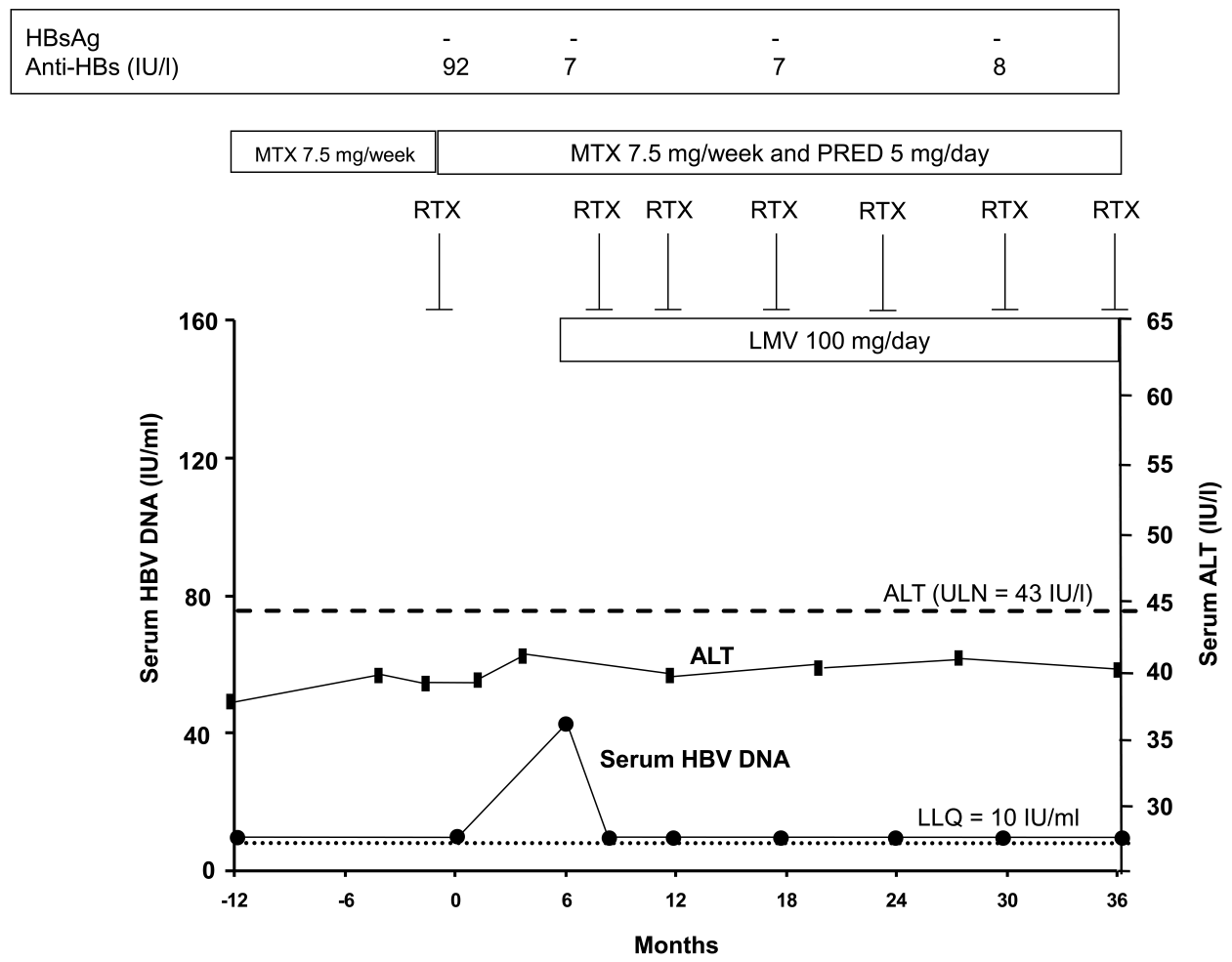

Figure 2. Time course of serum HBV DNA and serum ALT levels in the only patient experiencing HBV reactivation during treatment with RTX, MTX, and PRED who was rescued with LMV. HBV: hepatitis B virus; HBsAg: hepatitis B surface antigen; anti-HBs: HBsAg antibodies; ALT: alanine aminotransferase; RTX: rituximab; MTX: methotrexate; PRED: prednisone; LMV: lamivudine; ULN: upper limit of normal; Month 0: the time of starting RTX-based therapy. LLQ: low limit of quantification.

ruption or premature discontinuation of chemo-immunosuppressive therapy (thus compromising patient survival) or acute liver failure (which is associated with a mortality rate of up to $50 \%$ even if antiviral treatment is started at the time of reactivation $)^{6,10,11,12}$. This is important because there are about 1.6 billion people worldwide who are HBsAg-negative/anti-HBc-positive carriers ${ }^{22,23}$, a condition that predicts occult HBV infection ${ }^{7,8}$. These people continue to harbor residual HBV DNA in their livers that can be detected decades after the primary infection even though its replication is suppressed by the activity of antiviral T cells ${ }^{7}$.

However, little is known about the risk, predictive factors, and clinical consequences of HBV reactivation in patients with resolved HBV infection treated with RTX + DMARD for rheumatic disease, and their management is not clearly defined in the international clinical practice guidelines ${ }^{13,14,15}$. Only the European Association for the Study of the Liver guidelines recommend screening for anti-HBc in all patients who need immunosuppressive treatment, and advise testing for serum HBV DNA and treating those with ongoing viral replication with NUC as well as $\mathrm{HBsAg}$-positive patients ${ }^{13}$. In the same guidelines, some experts recommend anti-HBV prophylaxis for all anti-HBc-positive patients receiving RTX for hematological malignancies, bone marrow transplan- tation, or when close monitoring cannot be guaranteed, but no indications are provided for patients receiving RTX for other diseases.

Impaired immune control induced by immunosuppressive therapies may increase viral replication, which can lead to widespread liver HBV infection, severe flares of hepatitis, and liver injury after the recovery of immune competence ${ }^{24,25}$. To avoid this complication, 2 approaches have been suggested: universal prophylaxis, i.e., the administration of NUC before RTX-based treatment to all anti-HBc carriers to prevent an increase in HBV DNA levels and/or HBsAg seroreversion, or targeted prophylaxis, i.e., the administration of anti-HBV drugs after an increase in HBV DNA and/or HBsAg seroreversion has been detected before clinical signs of hepatitis reactivation.

However, although universal prophylaxis is clearly more beneficial than targeted prophylaxis in anti-HBc-positive carriers treated with RTX-based chemotherapy for oncohematological diseases ${ }^{11,26}$, there are very few data concerning the risk of viral reactivation in patients with RA undergoing RTX. A Greek study found no risk of HBV reactivation in 12 anti-HBc-positive carriers with rheumatic disease receiving $\mathrm{RTX}^{16}$, but this finding is affected by limited sample size, short followup (a median of $13 \mathrm{mos}$ ), the

Personal non-commercial use only. The Journal of Rheumatology Copyright (C) 2016. All rights reserved. 
lack of per protocol serum HBV DNA and HBsAg assessments during immunosuppressive treatment, and the fact that it is not clear whether the data refer only to the period of RTX treatment or also to the off-treatment followup. A recent Italian study found no risk of $\mathrm{HBV}$ reactivation among 14 patients with RA with resolved HBV infection who were treated with RTX plus DMARD for a median of 33 months ${ }^{17}$, but the study was limited by the fact that serum HBV DNA measurements were started some years after it began and, more importantly, that the evaluations were made only once a year, both of which may have led to HBV reactivation being missed in some subjects.

Our findings clearly extend previous results because they refer to the largest cohort of patients with RA with resolved HBV infection receiving RTX + DMARD and cover the longest period of followup available so far. It does have the limitation that its retrospective design may have affected the robustness of the interpretations, but its strengths include the fact that, although the patients were followed up in different clinics in Italy, they were all regularly monitored for HBV DNA and HBsAg, not only during RTX-based treatment, but also during the off-treatment followup period in the case of those who discontinued the drug. We acknowledge that these patients should be monitored with serum HBV DNA and/or HBsAg every 3 or 4 months for early detection of any asymptomatic increase of viremia or HBsAg seroreversion before clinical evidence of hepatitis. However, with a 6-month combined virological and serological monitoring, we may have missed only transient increases of serum HBV DNA, but none of the patients had HBsAg seroreversion and progressive increase of serum HBV DNA.

Overall, the available data indicate that universal anti-HBV prophylaxis is not justified in patients with RA with previous HBV infection undergoing RTX-based treatment. However, it is not clear why the risk of HBV reactivation is different in RTX-treated patients with rheumatological disorders and those undergoing RTX-based chemotherapy for oncohematological diseases. HBV reactivation is obviously made more complex in oncohematological patients because of differences in their immunosuppressive regimens and underlying diseases. However, the immunosuppression in our patients was undoubtedly significant because RTX was always combined with MTX (with or without steroids), and all of the patients had been previously treated for several years with other immunosuppressive regimens including anti-TNF agents.

Previous studies of oncohematological patients have found that low or negative baseline anti-HBs titers predict $\mathrm{HBV}$ reactivation in anti-HBc carriers receiving RTX-based chemotherapy ${ }^{27,28,29,30}$, and it could be argued that the high $(85 \%)$ prevalence of patients with protective anti-HBs titers at baseline in our cohort may have had a protective effect. However, although $21 \%$ of our patients with protective anti-HBs titers showed a significant reduction in titers during
RTX treatment and 2 patients had become anti-HBs-negative, no case of HBsAg seroreversion was observed. Moreover, it is interesting that the only patient who experienced the reappearance of serum HBV DNA during the first 6 months of RTX treatment showed an anti-HBs level decreased from 92 to $7 \mathrm{IU} / \mathrm{l}$ at the same time.

$\mathrm{HBsAg-negative/anti-HBc-positive} \mathrm{carriers} \mathrm{undergoing}$ RTX-based treatment for RA without anti-HBV prophylaxis have a negligible risk of reactivation, and so targeted prophylaxis based on monitoring serum HBV DNA and/or HBsAg levels and starting NUC in the case of an increase in serum HBV DNA and/or HBsAg seroreversion could be the recommended strategy. This notwithstanding, whenever regular HBV DNA and/or HBsAg level monitoring cannot be implemented, universal prophylaxis with LMV should be started. We believe that our findings are very important, not only because of the number of anti-HBc-positive patients worldwide, but also because of the increased use of RTX in patients with autoimmune disorders. However, further prospective studies of large populations with a longterm followup are still needed to clarify the effect of the concomitant administration of other immunosuppressive regimens and differences in the duration of RTX administration.

\section{REFERENCES}

1. Czuczman MS, Grillo-López AJ, White CA, Saleh M, Gordon L, LoBuglio AF, et al. Treatment of patients with low-grade B-cell lymphoma with the combination of chimeric anti-CD20 monoclonal antibody and CHOP chemotherapy. J Clin Oncol 1999;17:268-76.

2. Taylor RP, Lindorfer MA. Drug insight: the mechanism of action of rituximab in autoimmune disease - the immune complex decoy hypothesis. Nat Clin Pract Rheumatol 2007;3:86-95.

3. Coiffier B, Lepage E, Briere J, Herbrecht R, Tilly H, Bouabdallah $\mathrm{R}$, et al. CHOP chemotherapy plus rituximab compared with $\mathrm{CHOP}$ alone in elderly patients with diffuse large-B-cell lymphoma. N Engl J Med 2002;346:235-42.

4. Gürcan HM, Keskin DB, Stern JN, Nitzberg MA, Shekhani H, Ahmed AR. A review of the current use of rituximab in autoimmune diseases. Int Immunopharmacol 2009;9:10-25.

5. Gea-Banacloche JC. Rituximab-associated infections. Semin Hematol 2010;47:187-98.

6. Viganò M, Mangia G, Lampertico P. Management of patients with overt or resolved hepatitis B virus infection undergoing rituximab therapy. Expert Opin Biol Ther 2014;14:1019-31.

7. Raimondo G, Allain JP, Brunetto MR, Buendia MA, Chen DS, Colombo M, et al. Statements from the Taormina expert meeting on occult hepatitis B virus infection. J Hepatol 2008;49:652-7.

8. Pollicino T, Belloni L, Raffa G, Pediconi N, Squadrito G, Raimondo $\mathrm{G}$, et al. Hepatitis B virus replication is regulated by the acetylation status of hepatitis B virus cccDNA-bound $\mathrm{H} 3$ and $\mathrm{H} 4$ histones. Gastroenterology 2006;130:823-37.

9. Rituxan (rituximab) package leaflet. [Internet. Accessed January 18, 2016.] Available from:

www.gene.com/download/pdf/rituxan_prescribing.pdf

10. Yeo W, Chan TC, Leung NW, Lam WY, Mo FK, Chu MT, et al. Hepatitis B virus reactivation in lymphoma patients with prior resolved hepatitis B undergoing anticancer therapy with or without rituximab. J Clin Oncol 2009;27:605-11

11. Huang YH, Hsiao LT, Hong YC, Chiou TJ, Yu YB, Gau JP, et al. Randomized controlled trial of entecavir prophylaxis for

Personal non-commercial use only. The Journal of Rheumatology Copyright (C) 2016. All rights reserved. 
rituximab-associated hepatitis $\mathrm{B}$ virus reactivation in patients with lymphoma and resolved hepatitis B. J Clin Oncol 2013;31:2765-72.

12. Hsu C, Tsou HH, Lin SJ, Wang MC, Yao M, Hwang WL, et al; Taiwan Cooperative Oncology Group. Chemotherapy-induced hepatitis B reactivation in lymphoma patients with resolved HBV infection: a prospective study. Hepatology 2014;59:2092-100.

13. European Association For The Study Of The Liver. EASL clinical practice guidelines: management of chronic hepatitis B virus infection. J Hepatol 2012;57:167-85.

14. Lok AS, McMahon BJ. Chronic hepatitis B: update 2009. Hepatology 2009;50:661-2.

15. Artz AS, Somerfield MR, Feld JJ, Giusti AF, Kramer BS, Sabichi $\mathrm{AL}$, et al. American Society of Clinical Oncology provisional clinical opinion: chronic hepatitis B virus infection screening in patients receiving cytotoxic chemotherapy for treatment of malignant diseases. J Clin Oncol 2010;28:3199-202.

16. Mitroulis I, Hatzara C, Kandili A, Hadziyannis E, Vassilopoulos D. Long-term safety of rituximab in patients with rheumatic diseases and chronic or resolved hepatitis B virus infection. Ann Rheum Dis 2013;72:308-10.

17. Barone M, Notarnicola A, Lopalco G, Viggiani MT, Sebastiani F, Covelli M, et al. Safety of long-term biologic therapy in rheumatologic patients with a previously resolved hepatitis B viral infection. Hepatology 2015;62:40-6.

18. Gigi E, Georgiou T, Mougiou D, Boura P, Raptopoulou-Gigi M. Hepatitis $B$ reactivation in a patient with rheumatoid arthritis with antibodies to hepatitis B surface antigen treated with rituximab. Hippokratia 2013;17:91-3.

19. Salman-Monte TC, Lisbona MP, García-Retortillo M, Maymó J. Reactivation of hepatitis virus B infection in a patient with rheumatoid arthritis after treatment with rituximab. Reumatol Clin 2014;10:196-7.

20. Smolen JS, Landewé R, Breedveld FC, Dougados M, Emery P, Gaujoux-Viala C, et al. EULAR recommendations for the management of rheumatoid arthritis with synthetic and biological disease-modifying antirheumatic drugs. Ann Rheum Dis 2010;69:964-75.
21. Smolen JS, Landewé R, Breedveld FC, Buch M, Burmester G, Dougados M, et al. EULAR recommendations for the management of rheumatoid arthritis with synthetic and biological disease-modifying antirheumatic drugs: 2013 update. Ann Rheum Dis 2014;73:492-509.

22. Alter MJ. Epidemiology and prevention of hepatitis B. Semin Liver Dis 2003;23:39-46.

23. Lavanchy D. Worldwide epidemiology of HBV infection, disease burden, and vaccine prevention. J Clin Virol 2005;34 Suppl 1:S1-3.

24. Kim HY, Kim W. Chemotherapy-related reactivation of hepatitis B infection: updates in 2013. World J Gastroenterol 2014;20:14581-8.

25. Hwang JP, Lok AS. Management of patients with hepatitis B who require immunosuppressive therapy. Nat Rev Gastroenterol Hepatol 2014;11:209-19.

26. Buti M, Morillas R, Manzano ML, García-Retortillo M, Gutiérrez ML, Martín L, et al. Tenofovir for the prophylaxis of HBV reactivation in anti-HBc-positive patients with hematologic malignancies treated with rituximab: preliminary results of a randomized study (PREBLIN Study). J Hepatol 2014;60 Suppl:S421-2.

27. Kim SJ, Hsu C, Song YQ, Tay K, Hong XN, Cao J, et al. Hepatitis $\mathrm{B}$ virus reactivation in B-cell lymphoma patients treated with rituximab: analysis from the Asia Lymphoma Study Group. Eur J Cancer 2013;49:3486-96.

28. Ji D, Cao J, Hong X, Li J, Wang J, Chen F, et al. Low incidence of hepatitis $\mathrm{B}$ virus reactivation during chemotherapy among diffuse large B-cell lymphoma patients who are HBsAg-negative/ $\mathrm{HBcAb-positive:} \mathrm{a} \mathrm{multicenter} \mathrm{retrospective} \mathrm{study.} \mathrm{Eur} \mathrm{J} \mathrm{Haematol}$ 2010;85:243-50.

29. Koo YX, Tay M, Teh YE, Teng D, Tan DS, Tan IB, et al. Risk of hepatitis B virus (HBV) reactivation in hepatitis B surface antigen negative/hepatitis B core antibody positive patients receiving rituximab-containing combination chemotherapy without routine antiviral prophylaxis. Ann Hematol 2011;90:1219-23.

30. Pei SN, Ma MC, Wang MC, Kuo CY, Rau KM, Su CY, et al. Analysis of hepatitis B surface antibody titers in B cell lymphoma patients after rituximab therapy. Ann Hematol 2012;91:1007-12. 